\title{
AS DAMAS DA ASSISTÊNCIA À INFÂNCIA E AS AÇÕES EDUCATIVAS, ASSISTENCIAIS E FILANTRÓPICAS (RIO DE JANEIRO/RJ, 1906-1930)
}

\author{
DOI: http://dx.doi.org/10.1590/2236-3459/66363
}

\author{
Sônia Camara \\ Universidade do Estado do Rio de Janeiro (UERJ), Brasil
}

\section{$\cos 8$}

\begin{abstract}
Resumo
Este artigo visa refletir acerca do papel desempenhado pela Associação das Damas da Assistência à Infância que, criada em 1906, pelo Instituto de Proteção e Assistência à Infância do Rio de Janeiro, congregou mulheres da elite carioca na realização de iniciativas de assistência e de filantropia às crianças e às mães oriundas da pobreza. Para isso, elegemos, como foco de análise, os primeiros anos de funcionamento da Associação por consideramos que este período colabora para compreendermos o processo pelo qual se constituiu a conformação de um modelo de assistencialismo a ser realizado a partir, de então, pelas mulheres que compuseram a Associação, mas também de instituições congêneres criadas em vários estados do Brasil. Palavras-chave: damas da assistência à infância, Ipai, Arthur Moncorvo Filho, assistência, infância.
\end{abstract}

\section{THE LADIES OF ASSISTANCE TO CHILDREN AND EDUCATIONAL ACTIONS, AND ASSISTANCE CHARITABLE (RIO DE JANEIRO/RJ, 1906-1930)}

\begin{abstract}
This article aims to reflect about the role played by the Association of Childcare Ladies of which, created in 1906 by the Institute for the Protection and Care of Children of Rio de Janeiro, brought together women of Rio's elite in conducting relief efforts and philanthropy to children and mothers arising out of poverty. For this, we have chosen as the focus of analysis, the first years of operation of the Association for considering that this period contributes to understand the process by which constituted the formation of a model of welfare to be held from, then, by women formed the Association, but also created similar institutions in several states of Brazil.
\end{abstract}

Keywords: dames childcare, Ipai, Arthur Moncorvo Filho, assistance childhood.

\section{LAS DAMAS DE ASISTENCIA AL NIÑO Y ACCIONES EDUCATIVAS Y ASITENCIA NIÑOS CARIDAD} (RIO DE JANEIRO/RJ, 1906-1930)

\section{Resumen}

Este artículo tiene como objetivo reflexionar sobre el papel desempeñado por la Asociación de cuidado de niños de las señoras de las cuales, creada en 1906 por el Instituto para la Protección y cuidado de los niños de Río de Janeiro, reunió a las mujeres de la élite de Río en la realización de las actividades de socorro y filantropía para los niños y las madres derivadas de la pobreza. Para ello, hemos elegido como el foco de análisis, los primeros años de funcionamiento de la Asociación para considerar que este período contribuye 
a entender el proceso por el cual constituye la formación de un modelo de bienestar que se realizará del, entonces, por las mujeres formó la Asociación, sino que también creó instituciones similares en varios estados de Brasil.

Palabras clave: damas de guardería, Ipai, Arthur Moncorvo Filho, asistencia, infancia.

\section{LES DAMES DE L'AIDE AUX ENFANTS ET ACTIONS PÉDAGOGIQUES ET ASSISTANCE ENFANTS BIENFAISANCE (RIO DE JANEIRO/RJ, 1906-1930)}

\section{Résumé}

Cet article vise à réfléchir sur le rôle joué par l'Association des Childcare Ladies qui, créé en 1906 par l'Institut pour la protection et la garde des enfants de Rio de Janeiro, a réuni des femmes de l'élite de Rio dans la conduite des efforts de secours et de philanthropie les enfants et les mères résultant de la pauvreté. Pour cela, nous avons choisi comme la mise au point de l'analyse, les premières années de fonctionnement de l'Association pour considérer que cette période contribue à comprendre le processus par lequel constitue la formation d'un modèle de bien-être qui se tiendra du, puis, par les femmes formé l'Association, mais aussi créé des institutions similaires dans plusieurs Etats du Brésil.

Mots-clés: dames childcare, Ipai, Arthur Moncorvo Filho, assistance enfance. 


\title{
Introdução
}

Minhas Senhoras, - sinto-me neste momento profundamente feliz em ter podido acudir pressuroso ao apelo que este numeroso grupo de Mensageiras do Bem me dirigiu para assistir a uma solenidade como esta, tão grandiosa.

Pinard, o grande médico e filantrópico francês, já muito bem dissera: 'Entre as belas manifestações da solidariedade que caracterizam a evolução social neste fim do XIX século, devem ser colocadas em primeiras linhas as que têm por fim: tornar a vida melhor às mães e às crianças'.

(MONCORVO FILHO, 1907, p. 28, grifos nossos).

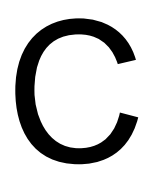

om estas palavras o presidente fundador do Instituto de Proteção e Assistência à Infância (Ipai) do Rio de Janeiro, o médico Arthur Moncorvo Filho iniciou o discurso de posse à primeira diretoria da Associação das Damas da Assistência à Infância. Na sessão solene realizada em 17 de setembro de 1906, no salão nobre do Ipai, o médico não deixou de enfatizar a missão exercida pela filantropia no socorro às mães e às crianças pobres, destacando a atuação exercida pelas mulheres, "mensageiras do bem", na cruzada desenvolvida pelo instituto em prol da proteção e do amparo à infância.

Caridade, filantropia e assistência constituíam-se como faces de um discurso que, objetivando atenuar à situação de precariedade da população pobre, assumiu força junto aos setores mais abastados da sociedade. A ação combinada da caridade e da assistência configurou-se como estratégia visando "remediar os males que assoberbavam à infância", instituindo-se como uma "nobre" missão a ser assumida em nome do bem da Nação (MONCORVO FILHO, 1907, p. 28). A observância aos preceitos higiênicos elementares, o socorro à pobreza, a atenuação da ignorância e a cura das doenças compunham a plêiade de problemas que necessitavam ser enfrentados. Nesta direção, Freire e Leony (2011, p. 202) defendem que, no pós proclamação da República, se deu um movimento de "convergência identitária entre saúde, educação e nação" que passou a guiar os movimentos reformadores por parte da intelectualidade, cujo eixo orientador assentava-se na profusão de iniciativas de cunho educativo e higiênico para a sociedade. Em concordância com essa compreensão, Mott, Byington e Alves afiançam que:

\begin{abstract}
Homens e mulheres das camadas médias e das elites passaram a denunciar e a buscar soluções para esse 'desperdício de vidas'. O país tinha solução, sim! Ao contrário do que se dizia, não era a mestiçagem nem o clima tropical que tornavam o brasileiro preguiçoso e dizimava a população. Os problemas eram decorrentes do analfabetismo e da falta de cuidado com saúde. Para reverter esse quadro, foram constituídas entidades de assistência médica e social voltadas para a infância, que passaram a divulgar propostas de combate à mortalidade infantil em discursos, aulas, palestras, seminários, publicações. Nascia uma nova sensibilidade em relação às crianças brasileiras, que passavam a ser consideradas fundamentais para o desenvolvimento e a renovação nacional. (MOTT; BYINGTON; ALVES, 2005, p. 39).
\end{abstract}

Mobilizados por uma intenção modernizadora do país, iniciativas privadas de caráter filantrópico e assistencial foram concebidas intentando responder às demandas sociais que à condição das crianças desvalidas requeria. Investida de uma missão civilizatória, setores da intelectualidade procederam à constituição de movimentos intervencionistas que tencionavam transformar a pobreza à luz da ciência. Assim, a pobreza foi apresentada enquanto fenômeno social que provocava desigualdade econômica e 
contribuía para o baixo nível de vida das crianças e de suas famílias, constituindo-se como atenuante à promoção de ações intervencionistas. Para Geremek, a pobreza exprimia-se pela existência de grupos sociais que vivam "na inferioridade e mais frequentemente na exploração, estigmatizados pela sociedade devido ao seu modo de viver". Seus comportamentos infringiam "as normas e os valores admitidos pelo complexo da sociedade". (1998, p. 220).

Em conformidade com a concepção de que era urgente atuar sobre a situação da infância oriunda da pobreza, o médico Moncorvo Filho e seus colaboradores, partícipes do Ipai, proclamavam a necessidade de se impor "preceitos científicos e higiênicos no cuidado físico, intelectual e moral da criança". Ações assistencialistas e educativas foram gestadas perspectivando atuar sobre as atitudes culturais consideradas impróprias e desviantes. Firmava-se, portanto, a importância da higiene privada, assentada na difusão dos "princípios relacionados ao cuidado da mãe com a prole", e da higiene pública na "promoção de medidas referentes à proteção da infância nos espaços públicos, nas fábricas e nas escolas, entre outros". (CAMARA, 2014a, p. 85).

Com intuito de se estabelecer estratégias de profusão da higiene e da assistência à infância, Moncorvo Filho recorreu às experiências empreendidas na Inglaterra, na França, na Alemanha, nos Estados Unidos da América do Norte e em países da América do Sul. Exemplar, no caso da América Latina, foi a iniciativa empreendida no Chile, onde as mulheres da cidade de Maule haviam criado, em 1898, a Associação das Damas Mauloises. A menção ao Chile é demonstrativa da intenção do médico em destacar ações realizadas em outros países no que se referia ao desvelo das mulheres que, para além do auxílio material, do socorro, do sustento moral, levavam "o calor aos lugares mais lôbregos e frios". Tomando como modelo de referência a experiência maulesa, o médico propugnava que a atuação das mulheres brasileiras deveria se organizar como um apostolado ancorado no exemplo, na palavra e na fé. (MONCORVO FILHO, 1907, p. 28).

Assim, a Associação das Damas da Assistência à Infância foi concebida como parte das estratégias acionadas pelo Ipai que, em acordo com as iniciativas que vinham se processando no cenário internacional, envidariam esforços na promoção e difusão dos preceitos de puericultura e de higiene infantil. Por meio de campanhas, cursos populares, folhetos e orientação às mães visaram colaborar para a difusão dos princípios associados aos cuidados com à infância (CAMARA, 2014a). Assente na compreensão de que mais forte que as leis eram os costumes, Moncorvo Filho defendia uma atuação educativa e exemplar, a ser exercida pelas Damas. Estas deveriam ser capazes de colaborar na correção dos maus hábitos e na normatização dos costumes como medidas eficazes na composição das campanhas do Bem a serem empreendias.

Tendo como premissa que a Associação das Damas da Assistência à Infância foi constituída como um braço importante e "auxiliar" da assistência e da difusão dos princípios de educação higiênica às mães pobres, empreendidas pelo Ipai, algumas questões emergem norteando nossas reflexões. Teria a Associação assumido apenas uma função prescritiva e auxiliar ao Ipai no amparo às crianças e às mães pobres? Em que medida a atuação das Damas da Assistência à Infância colaborou para a difusão/interiorização de modelos assistenciais à infância nas primeiras décadas do século XX? Até que ponto é possível pensar a Associação como um espaço de ampliação e de sociabilidades (SIRINELLI, 2003) para as mulheres que dela participaram? Partindo dessas questões- 
problema, este artigo visa refletir acerca do papel desempenhado pela Associação das Damas da Assistência à Infância que, criada em 1906, como braço filantrópico do Instituto de Proteção e Assistência à Infância do Rio de Janeiro, congregou mulheres da elite carioca no período de 1906 a $1930^{1}$.

Neste artigo elegemos, como foco de análise, os anos iniciais de funcionamento da Associação - primeira década do século $X X$-, por considerarmos que nesse período de abrangência deu-se a conformação de formas de atuação das Damas da Assistência, permitindo balizar os aspectos que compuseram o perfil de identidade e de composição de um modelo de assistencialismo a ser realizado a partir de então. Assim, interessa-nos examinar a Associação como espaço de sociabilidade formal onde as mulheres da elite carioca estabeleceram relações de afinidade, de identidade e de distinção. Objetivamos, então, problematizar a atuação das Damas para além do fluxo dos fazeres ordinários associados aos lugares domésticos de identidade da mulher, importa-nos refletir acerca dos jogos de poder mediante os quais puderam movimentar peças e instituir outros sentidos a esses lugares de ação social.

Desse modo, intentamos construir um duplo movimento analítico: no primeiro compreender a constituição da Associação, sua organização, o modus operandi a partir do qual congregou e cooptou adeptas na constituição de ações de benemerência e de assistência à infância pobre; na segunda destacar a atuação das Damas através dos projetos mobilizados, por elas, que permitiram a interiorização de um modelo de assistência tendo como referência as iniciativas e bandeiras empunhadas pelo Ipai. Compondo iniciativas de auxilio, de educação e de negociação, recorreram as sociabilidades informais mediante as quais puderam dar visibilidade às ações empreendidas dentro e fora do Ipai. Para realizar esse movimento interpretativo, recorremos às fontes documentais constituída por livros; relatórios e periódicos como: Revista ABC; Correio da Manhã, Revista Archivos de Assistência à Infância; os Estatutos da Associação das Damas da Assistência e o Boletim das Damas, que passaram a circular na revista feminina, A Faceira, a partir de $1911^{2}$.

\section{A Associação das Damas e a "santa cruzada do bem"}

Objetivando atuar como instância complementar ao instituto, a Associação das Damas da Assistência foi criada em 05 de setembro de 1906 e tinha como finalidade promover os meios de proteger eficazmente à infância pobre, proporcionando a difusão dos cuidados necessários ao seu desenvolvimento. Constituindo-se como braço filantrópico do Ipai e da "cruzada do bem", a Associação congregou mulheres que participavam do instituto desde sua criação, em 1899, bem como por um "número ilimitado de sósias" que se propuseram a participar da Associação, como consta em seus Estatutos. Segundo o jornal

\footnotetext{
${ }^{1}$ O Ipai manteve suas atividades até 1940, ano em que o instituto foi doado pelo seu fundador, o médico Arthur Moncorvo Filho, à municipalidade. As fontes pesquisadas, até o momento, permitem afiançar à manutenção das atividades da Associação das Damas até a década de 1920.

2 Atualmente estamos trabalhando na análise da Revista A Faceira, com especial atenção para os debates em torno da infância e da presença do Boletim das Damas, como parte constitutiva desse periódico. Em nossa compreensão, a revista assumiu um papel importante como veículo de difusão das ideias de benevolência junto à elite da capital, mas também de outros estados que adotaram experiências similares à desenvolvida pelo Ipai e, em especial, no que se refere à atuação das mulheres nas instituições de benevolência pública. Localizamos na Biblioteca Nacional exemplares da revista para o período de 1911 a 1916.
} 
Correio da Manhã, de 06 de setembro de 1906, "cerca de 1.500 nomes de senhoras da nossa melhor sociedade [...] foram convidadas para fazer parte da nova associação".

Com sede no Instituto de Proteção e Assistência à Infância, a Associação contou com apoio administrativo e de infraestrutura para a sua instalação e funcionamento por parte da instituição. O reconhecimento atribuído às Damas pelo médico Moncorvo Filho, sustentava-se, em parte, em sua compreensão acerca do papel "natural" da mulher no cuidado com a criança, mas também, na capacidade que tinham de transmitir os preceitos higiênicos e mobilizar ações de benevolência. Mediante uma atuação esclarecida e organizada, as Damas desempenhariam a mediação junto às mulheres pobres, às crianças e às mulheres de seu círculo social.

Fundada por senhoras e senhoritas da elite carioca, a Associação contou, especialmente com o empenho de um grupo de mulheres que participavam do Ipai, desde a sua fundação, em 1899. Congregando um "núcleo vigoroso [...] do que de mais fino possui a nossa sociedade, desde a esposa do Exmo. Sr. Presidente da República, de Ministros, Senadores, Deputados até as de pessoas outras muito conhecidas em nosso meio", a Associação congregou em torno da causa da infância escritoras, pintoras, advogadas, professoras e senhoras da sociedade. Entre elas: América Xavier, Isabel Moncorvo, Prescillan de Andrade, Germana Barbosa, baronesa de Salgado Zenha, Celeste Zenha de Moraes, baronesa de Mesquita, Bernardina Azeredo, Cecília Monteiro Mendes, Cacilda G. Fernandes, Hannah Mendes de Almeida, Anna Siqueira de Menezes, Guilhermina Moncorvo, Francisca Mello Mattos, Adelina Lopes Vieira, Paulina Dolbeth Andrade, Brazilina Guedes, Josephina Vianna.

A fim de estabelecer os critérios que iriam regulamentar o funcionamento da Associação, bem como reger a atuação das filiadas, foram propostos os Estatutos das Damas da Assistência à Infância. Este foi redigido em cinco capítulos: Capítulo I - Da Associação e dos seus fins; Capítulo II - Das Sócias; Capítulo III - Da Diretoria; Capítulo IV - Dos haveres da Associação e sua aplicação; Capítulo V - Disposições Gerais. Para composição dos Estatutos, as mulheres recorreram às proposições indicadas no Programa Geral do Ipai, o que se expressou na escrita do seu capítulo primeiro, artigo 4º das disposições sobre os fins da Associação:

a) Promover os meios de proteger eficazmente à infância pobre, proporcionandoIhe os cuidados de que carecer;

b) Angariar objetos que Ihe possam ser úteis à vida;

c) Incumbir-se, pelo trabalho de suas sócias, da confecção de vestes e do tratamento das crianças, quando enfermas;

d) Oferecer às crianças pobres festas e brinquedos por ocasião do Natal, Ano Bom e Reis;

e) Auxiliar o conselho administrativo do Instituto de Proteção e Assistência à Infância do Rio de Janeiro, sempre que este solicitar sua coadjuvação para a fiel execução do seu programa;

f) Promover, pelos processos que forem mais profícuos ao fim que deseja atingir, os recursos de que o instituto precisar para a sua permanente e condigna instalação. (ESTATUTOS DAS DAMAS, 1907, p. 20).

A análise dos seis princípios estabelecidos, permite captar a forma como as Damas arregimentaram esforços no sentido de validar a constituição da Associação no interior do instituto. Partindo dessas premissas, organizaram a Associação em 12 comissões com atribuições específicas e diretoria formada por presidente, secretaria, tesoureira e 
colaboradoras, como é demonstrado no Quadro 01, que segue.

Quadro 01 - Comissões da Associação das Damas da Assistência.

\begin{tabular}{|c|c|c|}
\hline Comissões & $\begin{array}{l}\text { Número de } \\
\text { Membros }\end{array}$ & Função \\
\hline 1a Sindicância & 12 & $\begin{array}{l}\text { Discutir as propostas para a admissão de sócias dando parecer } \\
\text { sobre sua aceitação ou recusa. }\end{array}$ \\
\hline $\begin{array}{l}2^{a} \\
\text { Contas }\end{array}$ & 12 & $\begin{array}{l}\text { Velar pela fiel aplicação dos haveres da Associação, levando ao } \\
\text { conhecimento da diretoria tudo o que Ihe parecer irregular. }\end{array}$ \\
\hline $\begin{array}{l}3^{a} \\
\text { Auxílio às Crianças } \\
\text { Pobres }\end{array}$ & 12 & $\begin{array}{l}\text { Promover a colocação das crianças em casas que lhe deem } \\
\text { trabalho de acordo com sua idade ou a colocação dos pais quando } \\
\text { dignas de proteção. }\end{array}$ \\
\hline $\begin{array}{l}4^{a} \\
\text { Assistência à } \\
\text { Crianças doentes }\end{array}$ & 12 & $\begin{array}{l}\text { Velar pelo bom tratamento das crianças internadas no } \\
\text { Instituto ou nele medicadas, cuidando do conforto e saúde, } \\
\text { concorrendo para o estabelecimento de sua saúde. }\end{array}$ \\
\hline $\begin{array}{l}5^{\mathrm{a}} \\
\text { Vestes }\end{array}$ & 20 & $\begin{array}{l}\text { Cuidar da confecção de vestes para as crianças pobres e } \\
\text { angariando donativos para o seu funcionamento. }\end{array}$ \\
\hline $\begin{array}{l}6^{\underline{a}} \\
\text { Festejos Internos }\end{array}$ & 12 & $\begin{array}{l}\text { Promover, uma vez por mês, diversões que distraiam e eduquem } \\
\text { as crianças, bem como aconselhando as mães sobre a melhor } \\
\text { forma de criar os seus filhos. }\end{array}$ \\
\hline $\begin{array}{l}7^{\mathrm{a}} \\
\text { Festejos Externos }\end{array}$ & 12 & $\begin{array}{l}\text { Promover a realização de espetáculos em teatros públicos, } \\
\text { regatas, corridas a cavalo, batalhas de flores, concertos e tudo que } \\
\text { possa reverter em verbas para a Associação. }\end{array}$ \\
\hline $\begin{array}{l}8^{\mathrm{a}} \\
\text { Donativos }\end{array}$ & 12 & $\begin{array}{l}\text { Angariar donativos, roupas, calçados, remédios, instrumental } \\
\text { cirúrgico, peças para curativos e tudo que possa minimizar } \\
\text { sofrimentos das crianças pobres, proporcionando-lhes alegria. }\end{array}$ \\
\hline $\begin{array}{l}9^{a} \\
\text { Previdência }\end{array}$ & 16 & $\begin{array}{l}\text { Promover junto dos poderes públicos a interdição das crianças } \\
\text { cujos pais houverem decaído do pátrio poder, entregando-se ao } \\
\text { vício da embriaguez ou a prática do roubo, torturando-as com } \\
\text { maus tratos, trabalhos exaustivos. Cabe, ainda orientar às mães } \\
\text { quanto a sua observância. }\end{array}$ \\
\hline $\begin{array}{l}10^{\underline{a}} \\
\text { Estudos }\end{array}$ & 12 & $\begin{array}{l}\text { Promover e auxiliar a manutenção das escolas e oficinas que o } \\
\text { Instituto criar, criar curso de estudos preliminares, onde ministrará } \\
\text { ensino às crianças em idade de aprender. }\end{array}$ \\
\hline $\begin{array}{l}11^{\mathrm{a}} \\
\text { Prédio }\end{array}$ & 30 & $\begin{array}{l}\text { Angariar donativos, cotas mensais, auxílios materiais, serviços } \\
\text { técnicos para a construção do prédio do Ipai. }\end{array}$ \\
\hline $\begin{array}{l}12^{-a} \\
\text { Festas de Natal, } \\
\text { Ano Novo e Reis }\end{array}$ & 12 & $\begin{array}{l}\text { Organizar presépio, banquete, baile, distribuição de brinquedos, } \\
\text { árvore de natal, bolo de Reis e tudo que edifique e divirta as } \\
\text { crianças pobres, nos três grandes dias que a cristandade } \\
\text { consagrou ao Natal, Ano Bom e Reis. }\end{array}$ \\
\hline
\end{tabular}

Fonte: Quadro organizado pela autora, a partir dos Estatutos das Damas da Assistência (1907, n. 1 e 2, p. 23-24).

A partir da aprovação dos Estatutos ficou determinada a composição da Associação e, nela, de sua diretoria. Entre suas atribuições, cabia representar os interesses das Damas em suas relações com terceiros e em juízo, bem como velar pela observância dos Estatutos 
e funcionamento da Associação. Ficava estabelecido que a diretoria seria eleita bienalmente e composta por sete sócias que se organizavam nos cargos de presidente, de vice-presidente, de duas secretárias, designadas numericamente de primeira e segunda, de tesoureira e duas procuradoras. Assim, definido os critérios de composição da diretoria, a 17 de setembro de 1906, foi empossada a primeira diretoria ${ }^{3}$ da Associação constituída pela senhora Bernadina Azeredo, presidente; a senhora Maria Antonietta Castro Cerqueira, vice-presidente; Germana Barbosa, tesoureira; Francisca Mello Mattos, primeira secretária; América Xavier, segunda secretária; Engracia Barroso Fernandes, primeira procuradora e Luiza de Oliveira Figueiredo, segunda procuradora. A primeira diretoria, no entanto, foi sorteada como indicado nas Disposições Gerais dos Estatutos, permanecendo até 14 de novembro de 1907, quando foi eleita a segunda diretoria:

A primeira Diretoria e as primeiras comissões da Associação das 'Damas da Assistência à Infância' serão tiradas à sorte de uma urna onde serão colocados os nomes de todas as sócias que comparecerem à sessão de instalação, anunciandose previamente para que cargo ou para que comissão se vai proceder ao sorteio. (ESTATUTOS DAS DAMAS, 1907, p. 26).

Em sua composição, a Associação e suas respectivas comissões eram constituídas por senhoras e senhoritas da sociedade carioca com moralidade reconhecida e maiores de 15 anos. Estas eram classificadas em quatro categorias de sócias: instaladoras, contribuintes, protetoras e beneméritas. Em sua regulamentação, os Estatutos definiam os direitos e os deveres relativos às associadas. Estabelecendo como direitos: a utilização do distintivo pela associada, o direito de votar, ser votada e encaminhar discussões nas seções promovidas pela Associação; como deveres: a obrigação de cumprir os estatutos, de trabalhar pelo progresso da Associação, de contribuir com os cofres sociais por meio do pagamento de mensalidades a serem determinadas de acordo com a categoria que a associada fosse enquadrada. As que não concorressem com a mensalidade fixada nos Estatutos seriam inseridas como sócias protetoras. Quando à filiada fosse identificada como sócia instaladora ou contribuinte, o valor da contribuição seria de $2 \$$; se protetora, o valor seria de \$1. (ESTATUTOS DAS DAMAS, 1907, p. 20-22).

Com o intuito de estabelecer um símbolo de distinção das Damas, foi instituído o uso do distintivo de associada. Este era conferido às sócias em alusão à sua pertença/filiação à Associação das Damas. Se por um lado, a filiação se materializava com o uso do distintivo; por outro se instituía pelo domínio de um código de aliança específico às associadas. Este configurava-se pela observância dos Estatutos e pela pauta que orientava as ações a serem exercidas pelas Damas, mas também, pela obediência aos preceitos que as qualificavam como "dignas" e "virtuosas" senhoras e senhoritas. Nesta perspectiva, é possível inferir que o ingresso à Associação forjava alianças que cindiam reciprocidades e solidariedades entre seus membros. A associação das mulheres à

\footnotetext{
${ }^{3}$ A segunda Diretoria (1907 a 1909) foi constituída pela Senhora Adelaide Vieira Maciel de Mello -Alfredo Pinto - (presidente); Dona Eugenia Ennes de Souza (vice-presidente); Dona Palmyra Bayma Guimarães (Tesoureira); Dona Arabella Cordeiro (1 ${ }^{\text {a }}$ Procuradora); Dona Ana Constança de Castro Cerqueira (1 ${ }^{a}$ secretária); Dona Carlota Labouriau ( $2^{\mathrm{a}}$ secretária); Dona Helena Oscar (2 $2^{\mathrm{a}}$ procuradora). Foi na gestão da Senhora Adelaide que foi criada a Creche do Ipai. Está recebeu o nome de Senhora Alfredo Pinto em alusão ao seu esposo, o Senhor Alfredo Pinto nome de destaque da política. Assumiu vários cargos públicos, inclusive como Ministro da Justiça e chefe de Polícia do Distrito Federal. Dona Adelaide foi renomeada presidente da Associação em 1909. (A FACEIRA, 1911, n. 3).
} 
instituição constituía-se, de tal modo, em possibilidades de se estabelecerem canais de comunicação, bem como de fronteiras, que colaboravam para a composição de identidades mediadas por interesses e valores que se firmavam no âmbito das pertenças de classe social, e também para além delas. (VELHO, 1989).

Deste modo, partimos da premissa que esse lugar de pertença social, instituído com a criação da Associação das Damas, possibilitou a produção de identidades específicas e de solidariedades na constituição de um "nós", de um coletivo em nome de uma causa comum compartilhada por essas mulheres que praticavam a benevolência no Ipai e as que foram se somando a elas. Irrompendo os muros de suas residências abastadas, tomaram contato com os espaços públicos, com as condições sociais adversas vividas pela população e, em especial, com as crianças pobres da cidade. O contato com os contrastes sociais que marcavam e cindiam à sociedade, em nossa compreensão, pode ter colaborado para a composição de solidariedades eletivas entre as mulheres/Damas, movimentada pela crescente sensibilização que a questão da infância passou a assumir em diferentes círculos intelectuais a partir dos finais do século XIX.

Desse lugar de atuação, as mulheres puderam mobilizar suas redes de sociabilidades informais produzindo trocas que se organizaram para além das condições sociais que as distinguiam, provocando acontecimentos. Acontecimentos que, por exemplo, envolviam a realização de festejos, promoção de concursos de robustez e de ações de assistência domiciliar e pública às mães pobres, distribuição mensal de socorro as crianças matriculadas no instituto. Reiteradamente, a imprensa apoiadora das iniciativas empreendidas pelo Ipai, como do jornal Correio da Manhã, das revistas da Semana, $A$ Faceira, Revista $A B C$ e outras, destacavam as ações beneméritas das Damas colaborando, também, na difusão do modelo de assistência empreendido pelo Ipai. Instituições congêneres ao instituto e, por extensão, de associações das Damas da Assistência foram criadas em cidades do Rio de Janeiro e diferentes estados do país ${ }^{4}$. A projeção do Ipai chegou ao estrangeiro, como demonstra Moncorvo Filho ao afirmar ter recebido um pedido de liberação de Madame Leyden, Presidente da Associação de Senhoras beneméritas da capital da Alemanha, para fundar naquele país um congênere do Ipai. (MONCORVO FILHO, 1927, p. 167).

Quanto à difusão dos Ipais e das associações das Damas pelo país é possível localizar iniciativas na Bahia, em 1903; em Pernambuco, em 1906; no Maranhão, em 1911; no Pará e na Paraíba, em 1912; no Ceará, em 1913; em Niterói, em 1914; entre outras. Nesse particular, os periódicos noticiavam as festas realizadas pelas Damas na cidade, como é demonstrativa a matéria de página inteira da "Revista ABC" de 04 de abril de 1925 em que, por um lado, exaltavam as ações do Ipai afirmando que: "graças ao Instituto de Proteção e Assistência à Infância, o Brasil conquistou um lugar entre as nações onde a pediatria se afirma", por outro aludiam o alcance e o empenho das Damas:

Domingo passado, no edifício de sua sede, em construção, efetuou o Instituto de Proteção e Assistência à Infância uma das suas festas das crianças pobres. Era a

\footnotetext{
${ }^{4}$ Congêneres da Ipai foram criadas em diferentes regiões do país, como: Bahia (1903), Pernambuco (1906), Rio Grande do Norte (1910), Ceará (1913), Belo Horizonte (1919), Ribeirão Preto (1919), Paraná (1921), sob a influência do Ipai do Rio de Janeiro. Instituições, como a Cruzada Pró-Infância, criada na cidade de São Paulo, por Pérola Byington, em 1930 constituiu-se em um exemplo de instituições que tiveram o Ipai como referência, assumindo outra designação. Cf: Mott; Byington; Alves, 2005.
} 
distribuição dos prêmios do $36^{\circ}$ Concurso de Robustez e essa foi solenizada com um banquete oferecido a 2000 crianças pobres. As Damas da Assistência à Infância, promotora desse festim aos petizes, e o ilustre pediatra patrício tiveram mais uma ocasião de pôr em destaque, ante as elites a finalidade eugênica e altruísta do Instituto. (REVISTA ABC, 04/04/1925).

Com a criação da Associação, formalizou-se os lugares de atuação para as mulheres no âmbito da filantropia e da educação higiênica no Ipai, no entanto esse movimento não impossibilitou que participassem em outras frentes, à exemplo do engajamento em ações profissionais no instituto. Para Sanglard (2014, p. 8-9), as mulheres tiveram desempenho expressivo no Ipai, como parteiras, como enfermeiras, na distribuição de leite esterilizado, na cirurgia dentária, na clínica médica, na distribuição de gêneros alimentícios, na helioterapia, na proteção à mulher grávida e na creche, criada em 1908. Nesta linha argumentativa, consideramos exemplares a participação da parteira Carlota Diniz de Oliveira Bem, das cirurgiãs-dentistas Isabella Von Sydone e Beatriz Tinoco Vieira. As três atuaram no Dispensário Geral Moncorvo e na Associação das Damas, simultaneamente, tendo a última participado, juntamente com outros médicos do Ipai, do IV Congresso Médico Latino-Americano o que consideramos ser um aspecto que indicia um lugar de destaque profissional alcançado, por ela, no Ipai.

Nessa direção, consideramos que a Associação das Damas se constituiu como um campo de possibilidade (VELHO, 1989), a partir do qual as mulheres puderam articular lugares distintos de atuação, mesmo que em pequena escala. A organização associativa $e$ a participação na esfera pública possibilitaram o fortalecimento de fazeres distintos aos relacionados à condição feminina à época, ou, ainda, à produção de outros laços de amizade e de estreitamento de identidades familiares. Nesta direção, aponta Sanglart (2014), a existência de grupos familiares atuando conjuntamente na instituição ${ }^{5}$.

A presença de senhoritas, filhas em muitos casos de mulheres que já atuavam profissionalmente ou na benevolência junto à Associação, a partir de 15 anos de idade como sócias, pode se configurar em um indício acerca do caráter educativo informal assumido pela associação. Além da perspectiva formativa das moças para desempenharem uma ação esclarecida como futuras mães, despertava-as para a benevolência pública como um legado familiar, uma herança de classe. Com essas iniciativas firmava-se a ideia da benevolência como um lugar próprio à mulher da elite $\mathrm{e}$, deste modo, como uma tradição imaginada.

Estudos produzidos por Melo e Nascimento (2010), acerca da atuação das Damas da Assistência do Instituto de Assistência à Infância do Maranhão, demonstram que a atuação das mulheres na experiência maranhense representou um esforço "muito tímido na conquista de maior visibilidade feminina", uma vez que a participação delas na instituição, constituiu-se como uma extensão da missão da mulher no cuidado com as crianças, bem como dos valores cristãos de caridade que envolvia a sua atuação (2010, p. 53). Asseguram as autoras que:

\footnotetext{
${ }^{5}$ Segundo a autora "[...] nota-se a presença de nomes importantes da política imperial vis à vis com figuras não menos importantes da Primeira República - tanto no cenário político quanto econômico". Este aspecto observado com relação ao Ipai, estende à Associação. Dos nomes apresentados pela autora quanto a presença de famílias atuando conjuntamente, destaca-se à família do Bem em que a parteira Carlota de Oliveira Bem, tinha as filhas Helena, Ester e Edith participando da Associação. (2014, p. 10-11).
} 
Para Moncorvo Filho (1914), as mulheres eram chamadas a este trabalho por estarem mais próximas das crianças, compreendendo melhor sua natureza, bem como suas necessidades. Segundo este médico, por saberem decifrar 'o mistério da alma', seus sorrisos e lágrimas foi-lhe dado, quase que naturalmente, a 'obra de alquimia moral que consiste em transformar a miséria, a ignorância e o vício, na saúde, na virtude e na felicidade'. [...] Vale destacar que, dentro dessa ótica, cabia à mulher apenas o papel de executoras das normas eugenistas e orientações médicas, elaboradas de modo hierárquico e verticalizado. Não estava ao seu alcance, portanto, elaborar o trabalho educativo do qual eram solicitadas a pôr em prática. (MELO; NASCIMENTO, 2010, p. 55).

Visando ampliar as possibilidades de análise acerca da atuação feminina ${ }^{6}$, pesquisas vêm se dedicado a refletir sobre o engajamento das mulheres nas associações assistenciais, colaborando, portanto, para problematizar outras dimensões acerca da participação dessas mulheres nas ações filantrópicas e assistenciais. Essas análises ensejam colaborar para que se possa dimensionar o papel desempenhado por elas na esfera pública, não apenas como marcas, exclusivas de submissão, mas como campo de possibilidade a partir do qual atuaram, produziram escolhas e construíram suas identidades. A experiência construída seria, assim, um "embrião de uma consciência de classe". Nessa perspectiva de análise, Freire (2013, p. 3) avalia que:

Críticos do modelo assistencial criado por Moncorvo Filho argumentam que a mobilização feminina acionada por seu Instituto representou simples modernização ou reforço à hierarquia de classe e gênero vigente nos primórdios da República. Os autores reconhecem que a Associação das Damas propiciou às mulheres da elite a possibilidade de ingresso na vida pública. Defendem, porém, que as atividades desenvolvidas no âmbito do Ipai restringiram-se àquelas consideradas como extensão natural da função doméstica feminina. (2013, p. 9).

Concordamos com Freire no que se refere a possibilidade que a criação da Associação das Damas de Assistência potencializou no sentido de facultar inserções diversificadas às suas filiadas. Defende a autora que mesmo nas atividades essencialmente práticas "incluídas no terreno da domesticidade, como a costura e a culinária" essas atividades realizadas em espaço público se investiram de nova dimensão, uma vez que permitiram empreenderem trocas de experiências assumindo, desta maneira, um "potencial transformar". (2013, p. 9).

O exame de jornais de época permite não somente identificar os critérios e os fins que regiam a Associação, mas também a possibilidade de pensarmos acerca dessas trocas e das dimensões assumidas a partir da atuação das mulheres, participantes da Associação. Para além de uma agenda de benevolência aos pobres, as Damas constituíram-se em força impulsionadora e articuladora do Ipai junto às famílias pobres, em especial às mães, mas também nos círculos da elite carioca.

Nessa perspectiva, as Damas atuaram de maneira a influir na normatização de hábitos higiênicos e de preceitos advindos com a pediatria e com as ciências afins, emergentes dos debates e estudos médicos encetados nas faculdades de medicina e nas Sociedades Científicas ${ }^{7}$, celeiros de profusão de teorias e debates acerca das doenças e

${ }^{6}$ Conferir os trabalhos de Bernardes (1989) e Freire (2013), entre outros.

7 O Ipai criou em 1902, uma Sociedade Científica que se organizou como espaço de ensino e de debates acadêmicos acerca de questões candentes aos cuidados com à infância. O espaço congregava o corpo médico profissional do Ipai e alunos da Faculdade de Medicina que, interessando-se pela puericultura passavam a atuar no instituto como assistentes. Os debates médicos eram provocados, em geral, pelos 
das causas de seu contágio. Para a difusão dos preceitos "autorizados", era preciso assegurar, como defende Engel (1989, p. 51) um poder de atuação sobre a rua, através da conversão da mulher em aliada, à luz do saber científico, único considerado legítimo na definição dos preceitos a serem difundidos junto às mães pobres.

O discurso médico sanitarista que se firmou, a partir do século XIX, sustentava-se numa perspectiva científica e cristã do amor materno em que as mulheres passavam a ser representadas como as guardiãs dos valores morais e responsáveis pelo cuidado da prole. Alma e corpo se somava. Com esta premissa, as Damas deveriam orientar as práticas no cultivo das crianças no aleitamento, no cuidado com os acidentes domésticos, na proliferação de doenças, despertando as mães para um repertório de questões que se instituía a partir de debates latentes acerca da composição da raça e dos efeitos da degenerescência provocado pelo desenvolvimento de doenças, como a sífilis, a tuberculose e o alcoolismo, mas também quanto aos riscos da não observância moral da infância.

\section{As mensageiras e o apostolado do Bem na salvação da infância}

A fim de atuar sobre as condições impróprias em que vivia a população, as Damas deveriam empreender esforços destinados a preservar a infância moral, intelectual e fisicamente para além de proporcionar auxílio no tratamento das doenças que, porventura, viesse a acometê-la. Por meio da "santa cruzada do Bem", as Damas deveriam atuar sobre a mortalidade, a natalidade e os problemas que enfermavam a sociedade, provocando o enfraquecimento da raça. Discursos eloquentes foram proferidos sustentados na perspectiva de que se realizava um combate do Bem contra o Mal. Como apóstolas do Bem, as Damas ressaltavam os princípios capazes de cooperar para a salvação da infância desvalida. Amparar a infância era a bandeira a ser empunhada pela Santa cruzada.

Parece-nos sugestivo a utilização, por parte dos filantropos, de expressões que remontam as experiências cristãs, a exemplo do uso corrente, pelos membros do Ipai, de referências às ações empreendidas pela instituição, como uma cruzada santa ${ }^{8}$ e, por outro, do uso corrente da expressão "apóstolas do Bem" para designar as Damas. Embora de inspiração católica, a referência pretendia sublinhar a força do movimento no sentido do que ele potencializava enquanto combate e doação dos que professavam a fé apoiados nos preceitos científicos de conversão e de imposição de axiomas científicos que deveriam ser propagados junto às famílias pobres. Nessa direção, o papel das Damas era o de professar à fé, converter e "doar" uma nova cultura, identificada com os preceitos advindos com a higiene. A intervenção sobre o social firmava-se, deste modo, na promoção da saúde e da higiene pública. Para isto, Moncorvo Filho defendia que:

[...] devemos constituir verdadeiros batalhadores d'essa cruzada do Bem a lutar pelas criancinhas desditosas, dando-lhes o conforto, o pão, a veste, o remédio, enxugando-Ihes as doridas lágrimas, levantando-Ihes enfim o moral abatido pelas

casos diagnosticados no instituto. Nesse particular, o Ipai funcionou como espaço de formação e de "reprodução de conhecimentos de uma especialidade nova na medicina que se caracterizou por estudar o corpo infantil". (LEVY, 1996, p. 84).

8 À alusão as cruzadas, remete aos movimentos de inspiração cristã que foram organizados na Europa Ocidental, durante os séculos XI ao XIII, visando conquistar, ocupar e manter o domínio cristão sobre a Terra Santa (Jerusalém). 
vicissitudes a que a ingrata natureza as arrastou. (MONCORVO FILHO, p. 52, grifos nossos).

O discurso do médico Moncorvo Filho e de alguns dos colaboradores do Ipai tinha na educação das mulheres pobres um de seus alvos privilegiados de ação, mas também das mulheres da elite que muitas vezes não observavam os preceitos de higiene defendidos pelo instituto. Colaborando desta preocupação, o médico Carlos Costa (1907), redatorchefe do jornal $A$ Mãi de Família ${ }^{9}$, em artigo publicado nos Archivos de Assistência à Infância, intitulado Preconceitos populares em relação à alimentação da primeira infância, afirmava que os esforços dos higienistas esbarravam nos preconceitos advindos das mulheres pobres, como também das que sabiam ler e ignoravam os ensinamentos advindos com o que preceituavam os médicos. Por meio da atuação organizada das mulheres, em torno da Associação das Damas, bem como da promoção de conferências de higiene infantil promovidas de 1901 a 1907, dos cursos populares organizados, em 1915, o médico Moncorvo Filho ambicionava impor uma cultura considerada apropriada e autorizada no cuidado com as crianças e, com isso, intervir no planejamento da vida social.

Estes preconceitos a que me refiro não são unicamente o apanágio da pobreza ou das camadas sociais inferiores. Nós médicos os observamos, mesmo nas classes elevadas da sociedade, na aristocracia [...]

Todos nós higienistas, continuamente em nossa infatigável propaganda, acusamos as mães ignorantes dos sofrimentos de seus filhos, devidos a má pratica seguida na alimentação da primeira infância, e, geralmente, são as pobres, as proletárias, que ficam ao alcance de nossas censuras; são as mães infelizes, que não sabem ler o que escrevemos, que não compreendem os nossos discursos, não dão valor ás nossas conferencias, as de que nos ocupamos, a servirão de exemplos para as nossas conclusões, em relação aos preconceitos populares.

Entretanto os preconceitos mais nocivos veem exatamente das que sabem ler os nossos escritos, das que compreendem os nossos discursos; pertencendo elas, porem à sociedade onde, antes de tudo, a gente se diverte, não nos leem, não assistem ás nossas conferencias, não querem distribuir ás outras ignorantes a esmola da sua educação intelectual, e pior ainda, dão-lhes maus exemplos da incredulidade e de sentimentos anti-maternais.

(COSTA, 1907, p. 151-152).

Como mensageiras do bem, às mulheres portadoras das boas novas, repassadoras de valores, de preceitos e de regras sociais, atuaram no convencimento das mães e, em especial, das mães pobres. Através de iniciativas que se materializavam na cidade capital, com a promoção de festas cristãs de Natal, de Ano Bom e de Reis; na distribuição de brinquedos; na promoção de banquetes, de bailes, no tratamento das crianças doentes, na publicação de orientações às mães publicadas nos Archivos de Assistência, bem como no agenciamento de ações visando angariar recursos ${ }^{10}$, essas mulheres projetaram-se em diferentes frentes de ação.

Quanto às festas de Natal, Ano Bom e Reis, assim foram apresentadas no Boletim

9 Sobre a importância do jornal como instrumento de propaganda às mães conferir o artigo de Camara (2014b). Nele a autora aborda o papel desempenhado pelo jornal na educação da infância. Como demonstra a autora, o jornal circulou de 1879 a 1888.

10 São significativos os dados relativos a arrecadação alcançada pelas Damas. De 05 de setembro de 1906 a 06 de setembro de 1913 a arrecadação das Damas foi superior a 50 contos, sendo de "52:815\$321 a receita (constando das quantias arrecadadas, mensalidades, donativos, festivais e saldos das comissões) e de 52:316 $\$ 083$ a despesa (constando de pagamento das vestes distribuídas, compra de brinquedos. (ARCHIVOS DE ASSISTENCIA À INFÂNCIA, 1914, p. 7-8). 
das Damas de 1913:

Com raro brilhantismo acabam de ser levada a efeito pelas incensáveis senhoras da Associação das Damas da Assistência à Infância as belas e tocantes festas de Natal, Ano Bom e Reis oferecidas a todas as crianças pobres que tiveram até hoje a felicidade de serem protegidas pelo humanitário Instituto de Proteção e Assistência à Infância do Rio de Janeiro que tantos serviços de beneficência publica vai prestando, graças à colaboração valiosa de distintos cavaleiros e sobretudo senhoras da nossa melhor sociedade.

Esses tradicionais festivais há cerca de 12 anos levados a efeito pela Assistência à Infância representam em nosso meio, uma encantadora nota do que valem a paz de uma bondade de coração ilimitado, o refinamento dos sentimentos de altruísmo pela sorte da infância sofredora, daquela que, fora das casas felizes onde é farto o alimento, onde gargalham as sedas e onde os brincos enchem os quartos dos pequeninos, só encontram o prazer e o conforto nos carinhos dessa Assistência que tudo lhe prodigalisa nessas ditosas datas em que devem esquecer as dores e alegrar o espírito.

(A FACEIRA, 1913, n. 18).

Ao tomarem as praças, os espaços escolares, os salões, os clubes na promoção de banquetes, de bailes, dos concursos de robustez infantil e das festas de Natal e Ano Bom, as Damas contribuíam para a ampliação do poder de alcance do Ipai a um público mais amplo do que o assistido pelo Ipai nas consultas, nos exames, na distribuição de leite esterilizado, no atendimento à mulher grávida e na doação de medicamentos nas instalações do instituto. Este aspecto pode ser mensurado pelos números de assistidos apresentados no balanço de 1913, no que se refere ao socorro aos necessitados. Para os anos de 1901 a 1913, a Comissão de Vestes apresentou a quantia de 19.735, crianças que receberam objetos; para o período de 1908 a 1913 foram distribuídos 214 enxovais para recém-nascidos pobres. (ARCHIVOS DE ASSISTENCIA À INFÂNCIA, 1914, p. 8).

Fazendo uso de uma retórica em que acionavam valores associados à família, à pátria e o futuro da nação as Damas buscaram convencer sobre os benefícios da cruzada em "prol dos pequeninos pobres" solicitando, para isso, auxilio do Estado para a cruzada, corporificada pelo Ipai (ARCHIVOS DE ASSISTÊNCIA À INFÂNCIA, 1907, p. 2-3). A prerrogativa educativa pode ser observada à medida que se identifica os festejos e os concursos como momentos em que, além da distribuição do alimento, das vestes, dos calçados, dos brinquedos e dos prêmios, objetivava-se difundir preceitos de civilidade e valores identificados à sociedade que se pretendia instituir, mediante as aspirações advindas com a Belle époque. A razão social que se arregimentava instituía-se a partir de um modelo hierárquico que definia uma cultura legítima assente em valores associados as formas de comer, de beber, de sentar, de vestir própria aos "civilizados". Com isso, firmouse a desqualificação da cultura popular (REVEL, 2009), identificada como inadequada no cuidado com a criança. Esse aspecto assume significação quando se observa, particularmente que o instituto funcionava em uma região de grande concentração de pobreza, a Praça Onze e a freguesia de Sant'Anna. Nestas regiões a força das reformas urbanísticas e sanitárias, advindas com a Belle époque, a partir especialmente das investidas promovidas pelo Prefeito Pereira Passos (1903-1906) não haviam conseguido suplantar de maneira efetiva a força dos costumes que marcava a forma como a população vivia.

Configurando-se como uma comunidade imaginada (ANDERSON, 2008), a Associação previu e produziu programas de atuação sobre à infância e às mães pobres. 
Se por um lado, prescreveram e organizaram ações a partir da compreensão que estas expressavam as demandas requeridas pela população; por outro pautaram as ações a serem promovidas, em concordância com os discursos higienista e eugenista em circulação à época. Assumindo uma agenda de benevolência, as Damas colaboraram na propagação das iniciativas caritativas, e de atendimento assistencial e educativa empreendidas pelo Ipai, colaborando na promoção das ações de assistência através das doações entregues ao Instituto a fim de contribuir na sua manutenção. Para os anos de 1907 a 1910 a quantia chegou a 20:400\$000 res.

O papel das senhoras numa cruzada da ordem desta é dos mais apreciáveis e dos mais nobres, e é por isso que ainda agora no último Congresso de Proteção à Infância na Bélgica realizado, com grande verdade afirmou Wiart, tratando das iniciativas a serem postas em prática, que: 'O esforço científico é insuficiente, se não são vivificados pela bondade, a compaixão e a ternura! O concurso da mulher deve dominar todas as obras de proteção à infância'. (MONCORVO FILHO, 1914, p. 9).

Por intermédio de suas redes de sociabilidade, as Damas empenharam seu prestígio de classe às ações realizadas e às demandas assumidas pelo Ipai. Para além do prestígio de classe empenharam, ainda, competências específicas na promoção de diferentes ações. No caso da Comissão de Ensino para o biênio de 1907 a 1909, era constituída pela advogada Mirthes de Campos, como presidente; Amélia Riedel Mendes da Silva, tesoureira; Iracema Orosco Freire, secretária e de Amélia Xavier, Maria dos Reis Campos, Thereza de Araujo Vianna, Belmira de Souza Ribeiro, Eugênia Ayque de Meira, Eulalia Rego Monteiro, Edina Iná de Oliveira Vaz, Hilda Freire de Carvalho e Emilia Lappot, como colaboradoras. A comissão tinha o objetivo de promover e auxiliar a manutenção de escolas e oficinas mantidas pelo Ipai, bem como oferecer grupos de estudos. Em seu quadro, a comissão contava com mulheres que, a exemplo de Maria dos Reis Campos, atuavam no magistério da municipalidade. Campos constituiu-se, na década de 1920, um nome de destaque no cenário educacional colaborando na reforma da instrução pública organizada pelo educador Fernando de Azevedo de 1927 a 1930, no Distrito Federal.

Para Sanglard, o sucesso alcançado por homens e mulheres da elite carioca decorreu da capacidade que tiveram de "dominar o código social e tirar o máximo proveito das oportunidades" (2014, p. 4). Nessa linha de argumentação, consideramos que as Damas souberam "manejar os códigos" sociais, lançando mão, sempre que necessário, de astúcias para disseminar os projetos associativos. Interessa observar que a participação das famílias da elite na benevolência representava um aspecto de distinção, mas também de doação ao outro e à pátria. Deste modo, a virtude era um dos critérios postulados às Damas. Por intermédio da concepção de virtude, corporificada nas ações realizadas por elas, enalteciam o bem comum em detrimento de um aparente proveito individual. Além de um caráter cristão e higiênico, as iniciações de assistência assumiram um sentido cívico, patriótico. Neste particular, a virtude era um preceito consagrado às mulheres da elite e à benevolência, o seu coroamento.

Imagens da benevolência pública eram estampadas pelas revistas e jornais cariocas dando a ver, por um lado, o retrato da pobreza socorrida pelo Ipai e; por outro, de que a pobreza assistida poderia ser robusta. A importância das medidas assentava-se na prerrogativa de que ao proteger a infância se estava trabalhando para o engrandecimento 
do país e o aprimoramento da raça. A perspectiva eugenista tomava forma e expressão, especialmente por intermédio dos concursos de robustez infantil organizados duas vezes ao ano. Estes foram capitaneados pela Associação a partir de sua instalação, em 1906. O concurso era constituído por um júri composto por médicos que a partir da análise dos dados apresentados pela criança - antecedentes familiares e minuciosos exames e medições - escolhiam a criança que amamentada pelo leite materno, corporificava o atributo de "sadia, forte, equilibrada de acordo com a sua faixa etária". (LEVY, 1996, p. 128).

Atuando como espelho da benevolência realizada, as Damas projetavam para fora da instituição, imagens do que se pretendia instituir como a face da benevolência e da assistência praticada pelo Ipai. Os eventos empreendidos nos salões e nos espaços públicos constituíam-se em oportunidades a partir das quais cindia-se sociabilidades a partir de redes de ligações e estratégias de investimento social. A Praça da República em muitas ocasiões foi palco das festividades e dos concursos de robustez infantil. Estratégias de difusão e de agenciamento de ideias contribuíram para o fortalecimento das medidas empreendidas pelo Ipai, a exemplo do Boletim das Damas que, a partir de 1911, passou a circular na Revista $A$ Faceira, periódico mensal de circulação nacional dedicado à vida feminina. O Boletim tinha, entre outros, o objetivo de divulgar e promover ações desenvolvidas pelas Damas influindo para a adesão das mulheres da elite à causa da infância. No primeiro número do Boletim, a revista destacou à premiação, com medalha de prata, alcançada pela Associação das Damas na Exposição Internacional de Higiene, enaltecendo, ainda, as ações realizadas em prol da infância pobre:

É um espetáculo encantador vê-las promover festivais donde colham os meios de adquirir os recursos, para as distribuições de leite esterilizado, de vestes, calçados e toda a sorte de outros benefícios que estão continuamente a prodigalizar à pobreza desta enorme cidade. Desperta imenso prazer vê-las semanalmente reunidas naquele Instituto, abençoado templo da Rua do Visconde do Rio Branco, congregadas ao redor de uma grande mesa à costurarem as roupas dos pobrezinhos.

[...] É enfim uma notável agremiação que precisa ser bem conhecida, em face mesmo da nossa civilização, uma associação como essa que opera prodígios de munificência, que tanta beneficência espace em favor das classes pobres, precisa alargar a sua área de ação, precisa multiplicar o número de suas associadas e não haverá certamente uma senhora habitando o nosso vasto Distrito Federal que, ao conhecer o acervo de benefícios que essa associação distribui, o seu valor moral, a sua grandeza de fins, para ela não concorra com todas as energias, não se associe a tão bondosas almas, cultivando com elas esse precioso sentimento de comiseração pela humanidade sofredora, imitando assim o sublime exemplo de $\mathrm{S}$. Vicente de Paula.

(A FACEIRA, 1911, n. 3).

Para além da ação educativa às mães, as Damas envolveram-se na criação, em 20 de julho de 1908, da creche Sra. Alfredo Pinto, segunda seção fundada pelo Ipai. Funcionado em duas salas do Ipai, com vinte e um leitos, a creche recebia crianças entre 20 dias e 2 e anos em dias úteis das 7 às 18 horas, mediante pagamento de uma mensalidade simbólica pelas mães. Além de fornecer alimentação e atendimento médico às crianças, a creche funcionava como espaço de aconselhamento às mães pobres. Nesta direção, o Boletim da Associação, publicou em 1911, o ABC das Mães, conselhos dados no Dispensário e na Creche Senhora Alfredo Pinto com a finalidade de demonstrar para as mães o seu dever social e patriótico. A ênfase envolvia o aleitamento materno e a sua 
importância na diminuição da mortalidade infantil, no cuidado com a higiene e no zelo à saúde das crianças. Assim, a criação da creche constitui-se em um indicativo da percepção, da Associação quanto a situação da mulher pobre que, necessitando trabalhar, não tinha como cuidar dos filhos. Juntamente com os médicos do Ipai, as Damas defendiam ser preciso preservar a infância moral, intelectual e fisicamente para além de curar as doenças que, porventura, viesse a acometê-las. Nesta direção, aspectos relacionados ao aleitamento materno e misto para o desenvolvimento da criança, indicações de higiene infantil entre outros temas mobilizavam a atuação das Damas, uma vez que a pobreza não deveria implicar na ausência de cuidados com a prole. Asseguravam, outrossim, que "zelando a saúde dos filhos" davam "as mães a maior demonstração da sua bondade e do seu amor" (A FACEIRA, 1911, n. 4). Por meio das ações empreendidas no âmbito da assistência e da filantrópicas, as Damas empreenderam o que se caracterizou como sendo a santa cruzada do Bem e, elas como as suas mensageiras.

\section{Considerações preliminares}

A análise das fontes de pesquisa selecionadas, evidenciam o destaque atribuído pelas participantes da Associação no intuito não somente de cumprir uma agenda de benevolência aos pobres, mas também de atuar em outras frentes. Neste sentido, mobilizaram comissões, organizaram campanhas educativas e ações em torno da importância da amamentação natural, dos cuidados higiênicos e do amparo à infância e às famílias. Aludiam o papel das mães no cuidado com a prole, sem deixar de considerar a competência do Estado na promoção de assistência e de auxílio às crianças pobres e abandonadas. É possível identificar em preleções organizadas em ocasiões festivas, a presença enfática de mulheres que atuando na Associação posicionavam-se defendendo ideias e arregimentando esforços no sentido de promover as ações do Ipai e angariar fundos para a sua manutenção.

A atuação dessas mulheres não se limitou a uma intervenção meramente protocolar de agenciamento de demandas instituídas pelo Ipai. Ao cruzarmos os aspectos que mobilizaram as Damas com os objetivos instituídos pela Federação Brasileira para 0 Progresso Feminino (FBPF), criada em 1922, localizamos pontos de contato importantes, como: a intenção de "coordenar e orientar esforços da mulher no sentido de elevar" o nível social da mulher; o propósito de "proteger as mães e a infância"; "estimular o espírito de sociabilidade e de cooperação entre as mulheres e interessá-las pelas questões sociais de alcance público" (SOIHET, 2000, p. 101). Todavia não seja possível identificar relações entre as Damas e os movimentos feministas, à época, é plausível, no entanto, afirmar que a presença de mulheres que exerciam diferentes misteres, como: escritoras, advogadas, professoras, cirurgiã-dentista, parteiras nos quadros da Associação e dos movimentos feministas, expressam um leque de possibilidades que nos lançam algumas outras questões que não se encerram neste artigo. Assim importantes demandas, como a instrução, o direito ao voto e a elegibilidade da mulher, mobilizaram os movimentos feministas que se organizaram, especialmente, a partir da década de 1920, sem deixar de considerar a "missão natural" da mulher no cuidado com a prole. (HAHNER, 1981).

Nesta direção, a incorporação e aceitação dos papéis femininos pôde significar não somente a submissão aos princípios preestabelecidos, mas também uma tática de reação, pela qual, as mulheres acionaram representações aceitas - de mãe/esposa - no 
estabelecimento e ampliação do seu espaço de atuação. Nesta linha de argumentação, defendemos que a atuação das Damas na Associação pôde comportar a possibilidade de alargamento, de reapropriação e de fabricação de outros sentidos, para muitas das mulheres que nela participaram, acerca dos fazeres associados ao papel social e biológico identificado à mulher. Importa considerar, ainda, que ao promover a assistência e a caridade à infância e às mães pobres da capital do país, as Damas ajudaram a compor e a difundir um modelo de assistência assente nos referenciais de ciência e de benevolência.

\section{Referências}

ALVES, Laura Maria Silva; ARAUJO, Sônia Maria da Silva. Assistência, proteção e direito à infância em Belém do Pará com a fundação do Ipai (1910-1912). International Studies on Law and Education, CEMOrOc-Feusp, IJI-Universidade do Porto, p. 29-38, jan./abr. 2016.

ANDERSON, Benedict. Comunidades imaginadas. São Paulo: Companhia das Letras, 2008.

CAMARA, Sônia. A arte de educar e prevenir crianças: as conferências de higiene infantil do Instituto de proteção e assistência à infância do Rio de Janeiro (1901-1907). In:

CAMARA, Sônia (Org.). Pesquisa(s) em história da educação e infância: conexões entre ciência e história. Rio de Janeiro: Quartet, 2014a.

. Em "prol dos pequeninos": o Instituto de proteção e assistência à infância como instância educativa e eugênica da família e da criança. In: ENCONTRO DA ASSOCIAÇÃO NACIONAL DE PÓS-GRADUAÇÃO EM HISTÓRIA (ANPUH), Minas Gerais, 2008. Anais... Minas Gerais: ANPUH, 2008.

. O jornal "A mãi de família" como estratégia de intervenção: higiene e educação da infância nos finais do século XIX. In: MIGNOT, Ana C. Venâncio; SILVA, Alexandra Lima da; SILVA, Marcelo Gomes da (Orgs.). Outros tempos, outras escolas. Rio de Janeiro: Quartet, 2014b.

Reinventando a Escola: o ensino profissional feminino na Reforma Fernando de Azevedo de 1927 a 1930. Rio de Janeiro: Quarter, 2013.

COSTA, Carlos. Os preconceitos populares em relação à alimentação da primeira infância. Archivos de Assistência à Infância. Rio de Janeiro: Editora Besnard Fréres, outubro, novembro, dezembro de 1907.

ENGEL, Magali. Meretrizes e Doutores: saber médico e prostituição no Rio de Janeiro (1840-1890). São Paulo: Editora Brasiliense, 1989.

FREIRE, Maria Martha de Luna. Gênero, filantropia e assistência materno-infantil: uma análise da atuação das damas de assistência do instituto de proteção e assistência à infância do Rio de Janeiro (Ipai). In: SEMINÁRIO INTERNACIONAL FAZENDO GÊNERO 10, UFSC, Florianópolis, 2013. Anais... Florianópolis: UFSC, 2013.

. Quando a caridade encontra a ciência: um olhar sobre a trajetória do dr. Moncorvo Filho. In: SANGLARD, Gisele; FERREIRA, Luiz O., et. al. Filantropos da nação: sociedade, saúde e assistência no Brasil e em Portugal. Rio de Janeiro: Editora FGV, 2015.

FREIRE, Maria Martha de Luna; LEONY, Vinícius da Silva. A Caridade científica: Moncorvo Filho e o Instituto de Proteção e Assistência à Infância do Rio de Janeiro (18991930). Revista História, Ciência, Saúde - Manguinhos, Rio de Janeiro, v. 18, supl. 1, p. 199-225, dez. 2011. 
GEREMEK, Bronislaw. Pobreza. Enciclopédia Einaudi, v. 38. Sociedade e Civilização. Imprensa Nacional, Casa da Moeda, 1998.

HAHNER, June. A mulher brasileira e suas lutas sociais e políticas: 1850-1937. São Paulo: Brasiliense, 1981.

LEVY, lete Cherem. A trajetória de Moncorvo Filho: puericultura e filantropia num projeto de assistência à infância (1901-1922). 1996. Dissertação (Mestrado) - Instituto de Filosofia e Ciências Sociais, Universidade Federal do Rio de Janeiro, Rio de Janeiro, 1996.

MELO, Jeane Carla Oliveira de; NASCIMENTO, Rita de Cássia Gomes. A regeneração dos costumes parte do alto: a atuação das damas de assistência do Instituto de assistência à infância do Maranhão (1911-1939). Revista Outros Tempos, v. 7, n. 9, p. 4160, 2010.

MONCORVO FILHO, Arthur. Em Torno do Berço. Conferência medico-social, realizada em 11 de março de 1914 no Cinema Odeon.

. Historico da Protecção á Infância no Brasil 1500-1922. Rio de Janeiro: Paulo, Pongetti \& Cia, 1927.

MOTT, Maria Lúcia; BYINGTON, Maria Elisa; ALVES, Olga Sofia. O gesto que salva. Pérola Byington e a cruzada pró-infância. São Paulo: Projetos Históricos e Editoriais, 2005, p. 46.

REVEL, Jacques. Proposições. Ensaios de História e Historiografia. Rio de Janeiro: EdUERJ, 2009.

REVISTA A FACEIRA. Rio de Janeiro: Redação Avenida Passos, ano 1, n. 3, outubro de 1911.

. Rio de Janeiro: Redação Avenida Passos, ano 1, n. 4, novembro de 1911.

Rio de Janeiro: Redação Avenida Passos, ano III, n. 18, janeiro de 1913.

REVISTA CARETA. Ano II, n. 84, 08 de janeiro de 1910. Hemeroteca da Biblioteca Nacional.

REVISTA ARCHIVOS DE ASSISTÊNCIA À INFÂNCIA. Rio de Janeiro: Imprensa Nacional, n. 1 e 2, 1907.

. Rio de Janeiro: Imprensa Nacional, n. 3 a 6, 1907.

Rio de Janeiro: Imprensa Nacional, n. 7 e 8, 1907.

Rio de Janeiro: Typografia Bersnard Fréres, n. 9, setembro de 1907.

Rio de Janeiro: Typografia Bersnard Fréres, ano VII, n. 1, janeiro a março de 1914.

SANGLARD, Gisele. Filantropia e política pública: Fernandes Figueira e assistência à infância no Rio de Janeiro na Primeira República. In: SANGLARD, Gisele; FERREIRA, Luiz Otavio., et al. Filantropos da nação: sociedade, saúde e assistência no Brasil e em Portugal. Rio de Janeiro: Editora FGV, 2015.

. Laços de sociabilidade no Rio de Janeiro - ação filantrópica e constituição de uma rede de assistência à infância (1889-1930). In: ARAUJO, Maria Marta Lobo; ESTEVES, Alexandra; COELHO, José Abilio (Coords.). Sociabilidades na vida e na morte (séculos XVI-XX). Portugal: CITCE, 2014.

SIRINELLI, Jean-François. Os intelectuais. In: RÉMOND, René (Org.). Por uma História Política. Rio de Janeiro: Fundação Getúlio Vargas, 2003.

SOIHET, Rachel. A pedagogia da conquista do espaço público pelas mulheres e a militância feminista de Bertha Lutz. Revista Brasileira de Educação, n. 5, p. 100, set./dez. 
2000.

VELHO, Gilberto. Subjetividade e Sociedade: uma experiência de geração. Rio de Janeiro: Jorge Zahar Editor, 1989.

SÔNIA CAMARA é Doutora em História e Historiografia da Educação, professora adjunta da Universidade do Estado do Rio de Janeiro (UERJ), atuando na graduação, no Programa de Pós-graduação Processos Formativos e Desigualdades Sociais da Faculdade de Formação de Professores e no Programa de Pós-graduação em Educação (Proped), da Faculdade de Educação. Na instituição coordena o Núcleo Interdisciplinar de Pesquisa em História da Educação e Infância (Niphei), desde 2007. Procientista da UERJ.

Endereço: Rua Miguel Ângelo, 661, ap. 404 - Cachambi - 20785224 - Rio de Janeiro - Brasil. E-mail: soniacamarauerj@gmail.com

Recebido em 21 de julho de 2016.

Aceito em 04 de novembro de 2016. 